\title{
Spatio-temporal pattern and driving forces of urbanization in China's border areas
}

\author{
SONG Zhouying ${ }^{1,2,3}$, ZHU Qiaoling ${ }^{1,2,3}$
}

1. Institute of Geographic Sciences and Natural Resources Research, CAS, Beijing 100101, China;

2. Key Laboratory of Regional Sustainable Development Modeling of the Chinese Academy of Sciences, Beijing 100101, China;

3. College of Resources and Environment, University of Chinese Academy of Sciences, Beijing 100049, China

\begin{abstract}
Border area is not only an important gateway for inland opening-up, but also an important part of completing the building of a moderately prosperous society and optimizing national urban spatial pattern in China. Due to the location, natural resources endowment, and traffic accessibility, the urbanization speed is relatively slow in border areas. Therefore, it is a special area that needs to pay close attention to, especially under the background of the Belt and Road Initiative and China's regional coordinated development program. Based on the county-level data from 2000 to 2015 , this paper tries to analyze the spatio-temporal pattern of urbanization in 134 border counties, and applies geographical detector method to study the driving forces of urbanization in border areas. Conclusions are as follows: (1) From 2000 to 2015, urbanization rate in border areas has been lower than the national average, and the gap has been widening. Some border counties in southern Xinjiang, Tibet, northeast of Inner Mongolia, and Yunnan, are even facing the problem of population loss. (2) In the same period, urbanization rate in the northwestern and southwestern border is low, while their urbanization rate grows relatively faster comparing with other border counties; urbanization rate in Tibet border is the lowest and grows relatively slowly; urbanization rate in the northeastern and northern border is slightly higher, but it grows slowly or even stagnates. (3) Transportation and industry are the important driving forces of urbanization in border areas, while the driving forces of market is relatively weak. And there are obvious mutual reinforcements among the driving forces, while the effort and explanatory power of resource force increases obviously after interaction. (4) Urbanization rate in the northwestern and southwestern border areas grows relatively fast, with industrial force and transportation force, market force and administrative force as the main driving forces respectively. Tibet border area has the lowest urbanization rate and growth rate, as the driving force of urbanization with strong contribution has not yet formed in Tibet. In the northeastern and northern border areas, the contribution of transportation force to urbanization is greater than other forces, and its interaction with market and industry has obvious effects.
\end{abstract}

Keywords: border area; urbanization; spatio-temporal pattern; driving force; China

Received: 2020-01-02 Accepted: 2020-02-20

Foundation: National Natural Science Foundation of China, No.41871120; Priority Research Program of Chinese Academy of Sciences, No.XDA20010102

Author: Song Zhouying (1982-), PhD and Associate Professor, specialized in economic geography and regional studies. E-mail: songzy@igsnrr.ac.cn 


\section{Introduction}

China's border areas are geographically remote and have poor transport connectivity and resource endowments. Population distribution in such areas is sparse, and there is little economic development momentum, and urbanization occurs slowly. The lower levels of urbanization in border areas has, to a certain extent, impeded the process of building a moderately prosperous society in all respects and optimizing the spatial layouts of cities and towns in China. In 2018, of China's 134 county-level administrative regions in border areas, 36 were key counties included in the national plan for poverty alleviation through development, which are areas that China focuses on to achieve coordinated regional development. On the other hand, border areas, especially border crossings, are important gateways to China's interior (Song et al., 2015). China's border trade has increased notably since 2013 due to the introduction of the Belt and Road Initiative, which has optimized the border market environment, promoted bilateral cooperation and driven the development of border areas. Given these circumstances, an in-depth analysis of the development of urbanization in China's border areas and research on its driving forces could be of significant help in optimizing China's urban structure, achieving coordinated regional development and advancing the construction of the Belt and Road Initiative.

Many scholars have studied urbanization patterns in China (Wang et al., 2012; Chen et al., 2014; Chen, 2016; Sun et al., 2016; Xue and Zeng, 2016). The urbanization process and its dynamic mechanisms, in particular, are popular topics in geographic research. Geographers have also explored the driving mechanisms of urbanization development in China from various angles. For example, Chen et al. (2009) found that the driving factors for urbanization have been diversified, with market force acting as the main driver, followed by intrinsic force, administration force and exterior force, in that order. Liu and Yang (2012) studied the drivers behind urbanization in Chinese counties and found that stage of economic development, fixed-asset investment, distance from a central city, levels of secondary and tertiary industries, rural net income per capita and population density are the main factors affecting urbanization in counties. Wang et al. (2016) conducted panel data analysis of 285 prefecture-level cities across China and found that labor, investment, economic development, government capacity, infrastructure and industrial structure play positive roles in stimulating urbanization. Gao et al. (2018) analyzed regional disparity and the influencing factors of land urbanization in China at the county level and concluded that population growth, economic development, industrial structure, city/county features and geographical location are the more important factors. Wu et al. (2018) believe that economic development level, urban features, population size, governmental decision-making behaviors, geographical location and regional disparity are the main factors that drive the coupling of demographic-landscape urbanization.

On the whole, research on China's urbanization tends to concentrate on the national level or on the central and eastern regions, with fewer studies looking at border areas. China's border areas are far from regional economic centers, and they are less urbanized than other parts of China. Moreover, due to their locations and environments, driving mechanisms of urbanization in border areas are necessarily different from other regions. In addition, given the importance of county and small- and medium-sized cities in the national economic de- 
velopment strategy, the urbanization of counties has increasingly become an important field of urbanization research (Liu and Yang, 2012; Gao et al., 2018). Within this context, this paper takes 134 county-level units in China's border areas as its research targets and uses geo-detectors and other analytical methods to study the urbanization trends of China's border areas from 2000 to 2015. It also attempts to build a border area urbanization drivers framework and conducts an in-depth analysis of those drivers, in order to further research on urbanization and border areas.

\section{Research framework}

\subsection{Unique features of urbanization in border areas}

Urbanization is occurring relatively slowly in China's border areas compared to the national rate of urbanization (Li et al., 2017; Wu et al., 2018). Drivers of urbanization are affected by the unique features of border areas' natural environment, transport connectivity and geopolitics, some of which are similar to previous research results, while others are not (Zhou et al., 2018).

The natural environment differs widely in China's border areas, with many unfavorable factors capable of restricting the development of urbanization. The Tianshan Mountains, the Himalayas and the Hengduan Mountains create barriers to external relations in border areas, which limit urban construction and spatial expansion. Moreover, many border counties in Inner Mongolia, Xinjiang and Tibet have cold and arid climates, and natural disasters occur frequently, increasing the cost of economic development and making them ill-suited to population concentrations.

Looking at population and society, border areas are home to high proportions of ethnic minorities. Most of these ethnic groups are distributed across borders, providing a social basis for interaction and cooperation with neighboring countries (Huang, 2010). Population density in border areas is relatively low due to the lack of a sufficient threshold population, higher education, entertainment, and even necessary infrastructure, which present obstacles to urbanization (Rumley and Minghi, 1991).

In terms of transportation, border areas require integration with both domestic and international markets. Domestically, border transportation routes are sparse. Border areas tend to be separated from domestic core markets and have a scattered economic spatial layout, both of which hinder the flow of factors of production ( $\mathrm{Li}$ et al., 2014). Internationally, most traffic networks stop at borders, with only a few trunk lines passing across national boundaries, and there are few border transportation hubs (Wang et al., 2018). However, with the implementation of the Belt and Road Initiative, connectivity between border areas and international markets has gradually increased, and border areas are no longer as isolated as they once were (Brunet-Jailly, 2005).

Cross-border economic and trade cooperation is an important economic activity in border areas. Different factor endowments and development levels on either side of a border encourage regional economic cooperation. Adding their geographical and cultural proximity, border areas tend to develop into functional spaces for sharing and exchanging resources (Tang et al., 2002; Su, 2013). But the "shielding" effect of borders may also hinder economic and trade exchanges (Huang, 2010).

In terms of geopolitical environment, border areas are not only buffer zones for safe- 
guarding national security but also strategically weak and sensitive areas ( $\mathrm{Hu}$ et al., 2012; Song et al., 2017). Their urbanization process is, therefore, susceptible to geopolitical influences. An unstable geopolitical environment may lead to large population loss, less openness and threats to border security, none of which are conducive to urbanization (Mao, 2013).

Looking at policy conditions in border areas, China's urban development is largely the result of capital accumulation and resource allocations guided by national and regional strategies, but the evolution of regional policies constantly changes the position of border area policies. The West China Development Strategy and the Belt and Road Initiative have created huge development opportunities for border areas.

In terms of industrial development, industries in border areas lag behind the rest of the country, while industrial structures tend to be relatively singular and industrial bases of urbanization tend to be relatively weak. The development of tourism resources in border counties, however, is highly valuable (Ma, 2003). And border tourism, which is a strategic industry for bringing prosperity to people in border areas ( $\mathrm{Li}$ and Shu, 2015), is an important way to adjust the industrial structure and promote urbanization in border areas (Qiu, 2005; Zhong et al., 2014).

\subsection{Urbanization drivers}

With consideration given to the unique features of border areas, and combining relevant drivers identified in existing research, this paper categorizes the driving forces of urbanization into natural force, administrative force, market force, industrial force, transportation force and social force (Table 1).

Natural force reflects basic natural conditions that are conducive to urbanization, including local livability and resources (Fang et al., 2012), and represents their ability to attract and accommodate an urban population. Natural force takes into account natural conditions and resources of border areas and is represented by the indicators of average annual precipitation, average annual temperature, average altitude and area of arable land.

Table 1 Drivers of urban development in China's border areas and their weights

\begin{tabular}{|c|c|c|c|c|c|}
\hline & Indicator & Units & Description & Data source & Weight \\
\hline \multirow[t]{4}{*}{ Natural force } & $\begin{array}{l}\text { Average annual } \\
\text { precipitation }\end{array}$ & $\mathrm{mm}$ & $\begin{array}{l}\text { Measures the livability of climatic } \\
\text { conditions via the average annual } \\
\text { precipitation of county-level units }\end{array}$ & $\begin{array}{l}\text { China Meteoro- } \\
\text { logical Data Service } \\
\text { Center (CMDC) }\end{array}$ & 0.25 \\
\hline & $\begin{array}{l}\text { Average annual } \\
\text { temperature }\end{array}$ & ${ }^{\circ} \mathrm{C}$ & $\begin{array}{l}\text { Measures the livability of climatic } \\
\text { conditions via the average annual } \\
\text { temperature of county-level units }\end{array}$ & $\begin{array}{l}\text { China Meteorolog- } \\
\text { ical Data Service } \\
\text { Center (CMDC) }\end{array}$ & 0.25 \\
\hline & $\begin{array}{l}\text { Average } \\
\text { altitude }\end{array}$ & $\mathrm{km}$ & $\begin{array}{l}\text { Measures the topographic conditions } \\
\text { in border areas via average elevation } \\
\text { of county-level units }\end{array}$ & $\begin{array}{l}\text { Geospatial } \\
\text { Data Cloud }\end{array}$ & 0.25 \\
\hline & $\begin{array}{l}\text { Arable } \\
\text { land area }\end{array}$ & ha & $\begin{array}{l}\text { Measures the scale of arable land in } \\
\text { border areas }\end{array}$ & $\begin{array}{l}\text { China Economic } \\
\text { and Social Devel- } \\
\text { opment Statistics } \\
\text { Database }\end{array}$ & 0.25 \\
\hline \multirow[t]{2}{*}{$\begin{array}{l}\text { Administrative } \\
\text { force }\end{array}$} & $\begin{array}{l}\text { Local fiscal } \\
\text { expenditure }\end{array}$ & $10,000 \mathrm{RMB}$ & $\begin{array}{l}\text { Measures the administrative and } \\
\text { regulatory capacity of local govern- } \\
\text { ments }\end{array}$ & $\begin{array}{l}\text { China Statistical } \\
\text { Yearbook } \\
\text { (County-Level) }\end{array}$ & 0.3 \\
\hline & $\begin{array}{l}\text { Public and pri- } \\
\text { vate fixed-asset } \\
\text { investment }\end{array}$ & $10,000 \mathrm{RMB}$ & $\begin{array}{l}\text { Measures the economic capacity of } \\
\text { local governments }\end{array}$ & $\begin{array}{l}\text { China Statistical } \\
\text { Yearbook } \\
\text { (County-Level) }\end{array}$ & 0.3 \\
\hline
\end{tabular}


(Continued)

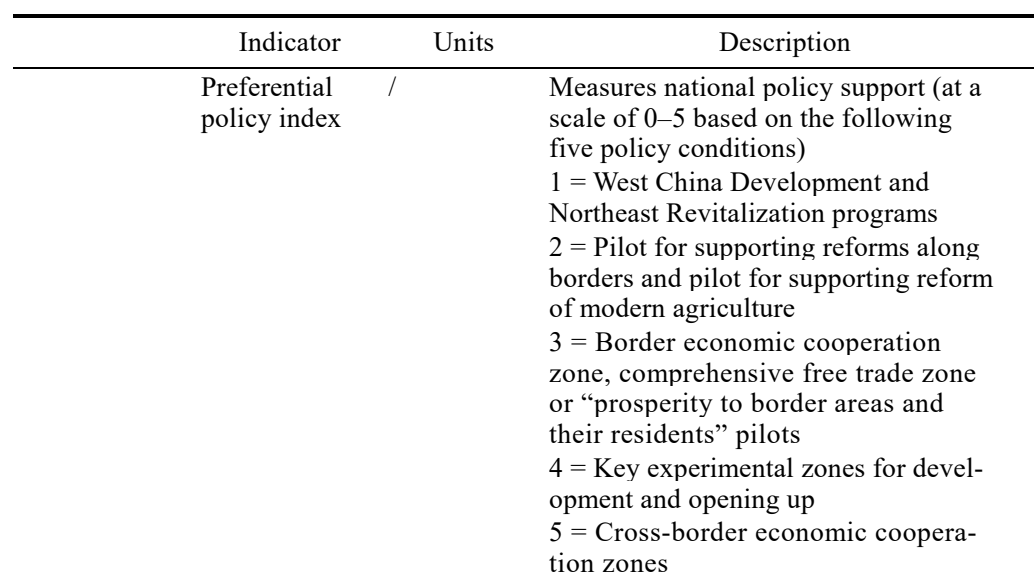

\begin{tabular}{|c|c|c|c|c|c|}
\hline \multirow[t]{4}{*}{ Market force } & $\begin{array}{l}\text { Total retail } \\
\text { sales of } \\
\text { consumer goods }\end{array}$ & $\begin{array}{l}10,000 \\
\mathrm{RMB}\end{array}$ & $\begin{array}{l}\text { Measures the size of domestic markets } \\
\text { in border areas }\end{array}$ & $\begin{array}{l}\text { China Statistical } \\
\text { Yearbook (Coun- } \\
\text { ty-level) }\end{array}$ & 0.4 \\
\hline & Bilateral trade & $\begin{array}{l}10,000 \\
\text { USD }\end{array}$ & $\begin{array}{l}\text { Measures the level of trade develop- } \\
\text { ment in border areas }\end{array}$ & $\begin{array}{l}\text { International Trade } \\
\text { Centre databases }\end{array}$ & 0.2 \\
\hline & $\begin{array}{l}\text { Bilateral econo- } \\
\text { mic integration }\end{array}$ & / & $\begin{array}{l}\text { Measures the bilateral trade environ- } \\
\text { ment (with integration scores of } 0-3 \text { ) } \\
0=\text { The two countries have no trade } \\
\text { agreement } \\
1=\text { Both countries have joined eco- } \\
\text { nomic organizations or agreements, } \\
\text { such as WTO, CAFTA, BRI, etc. } \\
2=\text { Countries are in bilateral trade } \\
\text { negotiations } \\
3=\text { Countries have signed a bilateral } \\
\text { free trade agreement }\end{array}$ & $\begin{array}{l}\text { Websites of Ministry } \\
\text { of Commerce and } \\
\text { National } \\
\text { Development and } \\
\text { Reform Commission }\end{array}$ & 0.2 \\
\hline & $\begin{array}{l}\text { Market oppor- } \\
\text { tunities }\end{array}$ & / & $\begin{array}{l}\text { Measures market size, market expecta- } \\
\text { tions, etc., of neighboring countries in } \\
\text { border areas (expressed as per capita } \\
\text { GDP of neighboring country/per capita } \\
\text { GDP of border area) }\end{array}$ & $\begin{array}{l}\text { China Statistical } \\
\text { Yearbook (Coun- } \\
\text { ty-level) \& World } \\
\text { Bank databases }\end{array}$ & 0.2 \\
\hline \multirow[t]{3}{*}{$\begin{array}{l}\text { Industrial } \\
\text { force }\end{array}$} & $\begin{array}{l}\text { Industrial } \\
\text { output }\end{array}$ & $\begin{array}{l}10,000 \\
\mathrm{RMB}\end{array}$ & Measures the level of industrialization & $\begin{array}{l}\text { China Statistical } \\
\text { Yearbook (Coun- } \\
\text { ty-level) }\end{array}$ & 0.4 \\
\hline & $\begin{array}{l}\text { Tourism } \\
\text { revenue }\end{array}$ & $\begin{array}{l}\text { Million } \\
\text { USD }\end{array}$ & $\begin{array}{l}\text { Measures the level of development of } \\
\text { tourism }\end{array}$ & $\begin{array}{l}\text { China Statistical } \\
\text { Yearbook }\end{array}$ & 0.3 \\
\hline & GRP & $\begin{array}{l}100 \text { million } \\
\text { RMB }\end{array}$ & $\begin{array}{l}\text { Measures overall industrial develop- } \\
\text { ment }\end{array}$ & $\begin{array}{l}\text { China Statistical } \\
\text { Yearbook (Coun- } \\
\text { ty-level) }\end{array}$ & 0.3 \\
\hline \multirow[t]{3}{*}{$\begin{array}{l}\text { Transportation } \\
\text { force }\end{array}$} & $\begin{array}{l}\text { Transport route } \\
\text { density }\end{array}$ & $\mathrm{km} / \mathrm{km}^{2}$ & $\begin{array}{l}\text { Measures level of transportation access to } \\
\text { China's hinterland (the ratio of the length } \\
\text { of transport routes to the administrative } \\
\text { area, including road and rail routes) }\end{array}$ & $\begin{array}{l}\text { China Statistical } \\
\text { Yearbook }\end{array}$ & 0.4 \\
\hline & $\begin{array}{l}\text { Transport } \\
\text { status }\end{array}$ & / & $\begin{array}{l}\text { Determines whether a county is an } \\
\text { important transportation node in } \\
\text { China's opening up drive }\end{array}$ & $\begin{array}{l}\text { Websites of Ministry } \\
\text { of Commerce and } \\
\text { National } \\
\text { Development and } \\
\text { Reform Commission }\end{array}$ & 0.3 \\
\hline & $\begin{array}{l}\text { Air transport } \\
\text { development }\end{array}$ & / & $\begin{array}{l}\text { Measures the level of aviation devel- } \\
\text { opment }(0-3 \text { assigned based on airport } \\
\text { construction) } \\
0=\text { No airport of category } 3 \mathrm{C} \text { or higher } \\
1=\text { has a } 3 \mathrm{C} \text { airport } \\
2=\text { has a } 4 \mathrm{C} \text { airport } \\
3=\text { has a } 4 \mathrm{D} \text { airport }\end{array}$ & $\begin{array}{l}\text { General } \\
\text { Aviation } \\
\text { Resource Net } \\
\text { of China }\end{array}$ & 0.3 \\
\hline
\end{tabular}


Continued)

\begin{tabular}{|c|c|c|c|c|c|}
\hline & Indicator & Units & Description & Data source & Weight \\
\hline \multirow[t]{3}{*}{ Social force } & $\begin{array}{l}\text { Proportion of } \\
\text { population } \\
\text { made up of } \\
\text { ethnic mi- } \\
\text { norities }\end{array}$ & 1 & $\begin{array}{l}\text { Measures social and cultural integration } \\
\text { with neighboring countries }\end{array}$ & Census & 0.4 \\
\hline & $\begin{array}{l}\text { Education } \\
\text { level }\end{array}$ & People & $\begin{array}{l}\text { Number of primary and secondary school } \\
\text { students and ordinary middle school stu- } \\
\text { dents per } 10,000 \text { people }\end{array}$ & $\begin{array}{l}\text { China Statistical } \\
\text { Yearbook } \\
\text { (County-level) }\end{array}$ & 0.3 \\
\hline & $\begin{array}{l}\text { Medical care } \\
\text { level }\end{array}$ & Beds & $\begin{array}{l}\text { Number of beds in medical institutions per } \\
10,000 \text { people }\end{array}$ & $\begin{array}{l}\text { China Statistical } \\
\text { Yearbook } \\
\text { (County-level) }\end{array}$ & 0.3 \\
\hline
\end{tabular}

Administrative force reflects the preferential rights provided to regions by national or local policies to support better allocations of funds, land or other factors of production to achieve economic construction and urban development (Lin, 2002; Cao and Liu, 2011). This paper uses local fiscal expenditure, public and private fixed-asset investment and preferential policies as indicators of administrative drivers.

Market force measures the size and potential of domestic and foreign markets. Given that the development of cities and towns in China's southwest border areas is driven by border trade (Song et al., 2017), this article uses the indicators of border trade, economic integration of trade partners and degree of market integration (Kelejian et al., 2012).

For industrial force, the three indicators of gross regional product (GRP), industrial output and tourism income are chosen to represent overall economic scale, industrial development and industries with prospects and advantages in border areas (Shen et al., 2005; Yao et al., 2008; Zhai et al., 2010).

Transportation force measures the degree to which border areas act as cross-border transport corridors to both China's hinterland and external markets, including both land- and air-based transportation (Wang et al., 2003; Ji et al., 2017). This study uses transportation route density, status of outward transportation channels and air transport as its three indicators.

Social force reflects regional social welfare levels and includes the indicators of medical care and education in this study. In addition, because border areas tend to be home to concentrations of ethnic minorities in China, the proportion of the population of an area that is made up of ethnic minorities is also used as an indicator.

Regarding the weights of the various indicators, first, this article referred to existing literature and field research data to preliminarily assign weights to each indicator. Weights were then revised based on field surveys and interviews with government officials, company leaders and individual businesses in border areas. In addition, opinions of relevant personnel at the National Development and Reform Commission's West China Development Department and experts in border areas were sought to finalize the weight of each indicator (see Table 1 for details).

\section{Research methods and data}

\subsection{Research methods}

(1) Coefficient of Variation

This paper uses the coefficient of variation (CV) to measure spatial differences in levels 
of urbanization in border counties, that is, the standard deviation of urbanization levels in 134 border counties divided by the mean.

(2) Geo-detectors

In this paper, geo-detectors are used to explore driving factors of urbanization in border areas and interactions between drivers. Geo-detectors are a group of statistical tools that detect spatial differentiation and reveal the driving forces behind them (Wang et al., 2010; Li et al., 2017). This study uses factor detector and interaction detector.

Factor detector is mainly used to measure the explanatory power of different driving forces regarding urbanization. The equation for calculating it is as follows:

$$
q_{D, H}=1-\frac{1}{n \sigma^{2}} \sum_{h=1}^{\mathrm{L}} n_{h} \sigma_{h}{ }^{2}
$$

wherein, $q_{D, H}$ is the explanatory power of driver $\mathrm{D}$ on urbanization level $\mathrm{H} ; n$ and $\sigma^{2}$ are the sample size and variance, respectively; and $n_{h}$ and $\sigma_{h}$ are the sample size and variance of geographical stratum $h(h=1,2 \ldots \mathrm{L})$, respectively. The range of $q_{D, H}$ is $[0,1]$, and the larger the value, the greater the explanatory power of the driver on the level of urbanization, wherein, 1 indicates that a driver is completely related to urbanization level.

Interaction detector is used to identify the interactions between multiple main driving factors; that is, whether driving factors $\mathrm{X}_{1}$ and $\mathrm{X}_{2}$ increase or decrease the explanatory power of dependent variable $\mathrm{Y}$, or whether their effects on $\mathrm{Y}$ are independent.

\subsection{Study area}

As can be seen in Figure 1, the study area of this paper contains 134 China's border-area counties. To facilitate analysis, the border areas have been divided into five regions based on

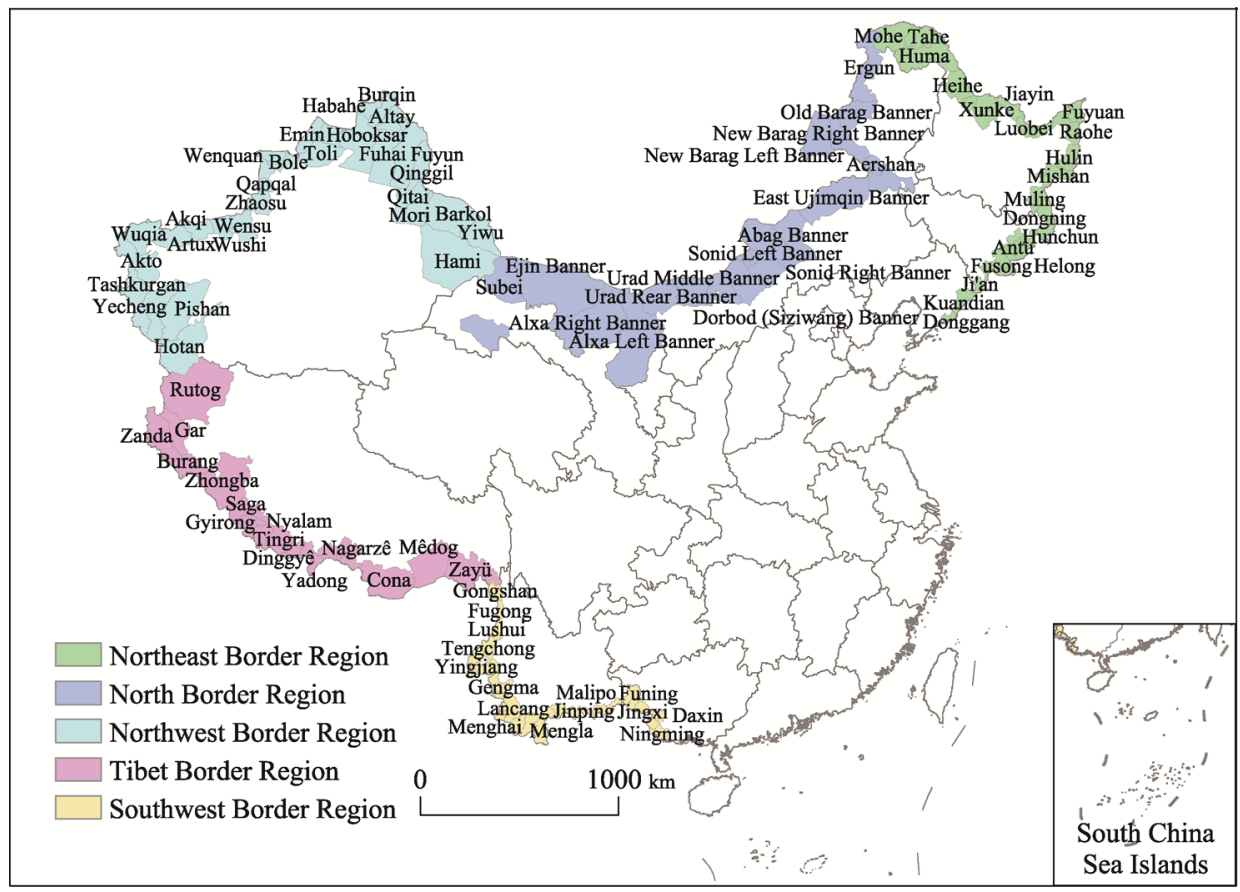

Figure 1 Study area (China's border areas) 
their socio-economic and natural environmental features. They are the Northeast Border Region, which consists of border-area counties in the three provinces of China's northeast (Liaoning, Jilin and Heilongjiang); the North Border Region, composed of border-area counties in Inner Mongolia and Gansu; the Northwest Border Region and Tibet Border Region, made up of border-area counties in Xinjiang and Tibet, respectively; and the Southwest Border Region, consisting of border-area counties in Yunnan and Guangxi provincial-level areas.

\subsection{Data sources}

The urbanization level of a border area is measured as the percentage of the resident population living in urban areas based on data from the fifth and sixth national censuses of China and supplemented with data from the China Statistical Yearbook (County-Level). Where no population data was available for some border counties for certain years, the United Nations' algorithm for estimating population was used to calculate population. Natural environmental and resource data, such as precipitation, temperature, altitude and arable land area, are sourced from the China Meteorological Data Service Center (CMDC), Geospatial Data Cloud, and Economic and Social Development Statistics Database. Data on preferential policies is mainly from official websites, such as the Ministry of Commerce and National Development and Reform Commission, as well as the State Council's list of key border areas contained in the State Council's Opinions on Supporting the Development and Opening-Up of Key Border Areas. Data on GDP, trade agreements, and so on concerning neighboring countries comes from official websites, such as databases of the World Bank and International Trade Center.

\section{Development of urbanization in border areas}

\subsection{Development trends}

From 2000 to 2015, the urbanization level of China as a whole constantly increased, but urbanization in border areas was constrained by factors such as remoteness and underdeveloped transportation. This meant that the rate of urbanization in such areas grew rather slowly, the level of urbanization in such areas was lower than the national average and the gap be-

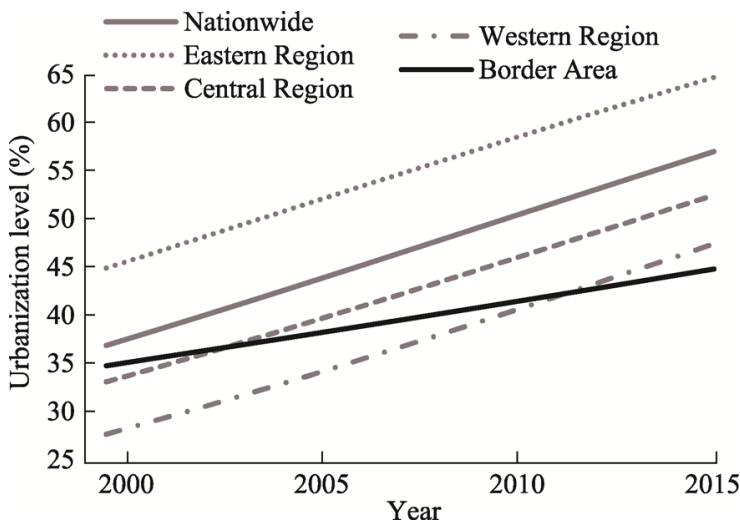

Figure 2 Changes in average urbanization level by region, 2000-2015 tween those areas and the national average continued to widen. As shown in Figure 2, in 2000, the average urbanization level in border areas was $34.81 \%$, which was higher than China's western and central regions at that time and close to the national average. Since then, with the implementation of regional development strategies such as the West China Development Program and the rise of the central region, urbanization in those places has increased rapidly; whereas, it has increased relatively slowly in border 
areas. As a result, the level of urbanization in border areas was surpassed by the central region in 2003 and by the western region in 2012. In 2015, the level of urbanization in border areas was $44.84 \%$, which was lower than in the central and western regions and 12 percentage points lower than the national average.

\subsection{Spatio-temporal features}

Between 2000 and 2015, the coefficient of variation (CV) index of urbanization in border areas dropped from 0.713 to 0.520 , indicating the obviously reduced spatial disparity. However, the spatial pattern of urbanization in border areas did not change notably. The urbanization level was higher in the Northeast and North Border Regions and lower in the Northwest, Tibet and Southwest Border Regions. In accordance with the classification of natural breaks, the urbanization levels of border-area counties are divided into five classes (using $25 \%, 40 \%, 55 \%$ and $70 \%$ as the dividing points): very low, low, medium, high, and very high (see Figure 3).
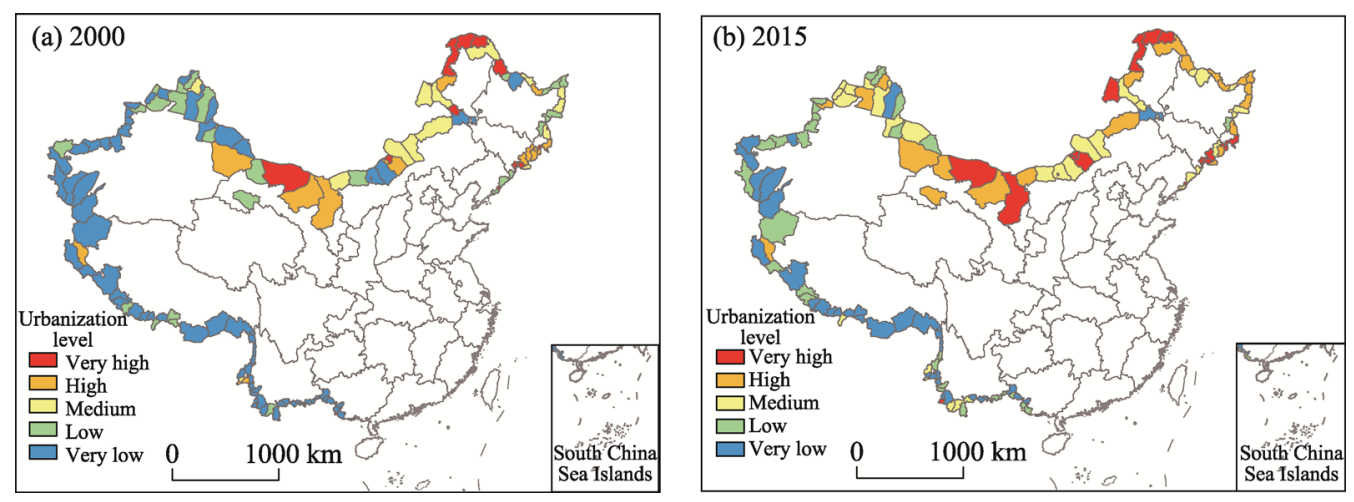

Figure 3 Spatial characteristics of urbanization in China's border areas, 2000-2015

In the year 2000, the urbanization levels of all counties in the Northwest, Tibet and Southwest Border Regions (with the exception of Fangchenggang, Dongxing, Pingxiang, Mangshi, Longchuan, and Ruili in the Southwest Border Region; Gar in the Tibet Border Region; and Altay and Hami in the Northwest Border Region) were below 40\%, which meant they were in the low or very low classes. Of those border-area counties, the urbanization levels of Zhongba, Saga, Tingri and Gamba in Tibet were below 5\%, the lowest in the country. In the Northeast and North Border Regions, other than the counties of Xunke, Jidong, Suibin, Fuyuan, Kuandian and Donggang on the northeastern border, and Horqin Right Front Banner, Dorbod (Siziwang) Banner, Damao United Banner and Urad Middle Banner on the northern border, the urbanization levels of all other counties were higher than $40 \%$, which meant they were in the medium, high or very high classes. Among them, Erenhot, Manzhouli, Aershan, Mohe and Tahe had the highest levels of urbanization, all exceeding $90 \%$.

In 2015, urbanization levels in the counties of Bole, Tacheng, Fuhai and Qitai in the northern part of the Northwest Border Region, the Subei Mongol Autonomous County, Alxa Left Banner and Dorbod (Siziwang) Banner in the central part of the North Border Region, and Huma, Tongjiang, Fuyuan, Dongning, Hunchun and Fuyuan in the eastern part of the 
Northeast Border Region increased significantly. Urbanization rate in counties in the northern part of the Northwest Border Region rose above the medium level, but urbanization levels in Hotan, Pishan, Wushi, Yecheng and Akto were still below 20\%. The urbanization levels of counties in the Southwest Border Region increased slightly, but those of counties in the Tibet Border Region remained low. The urbanization levels of most counties in the Northeast Border Region and North Border Region were higher than 55\%, putting them in the high or very high classes. The urbanization levels of both the Horqin Right Front Banner and Muling were below $40 \%$.

\subsection{Development model}

Between 2000 and 2015, the growth rate of urbanization in border areas slowed overall. During that time, the urbanization levels of most counties increased less than $10 \%$, and the levels of some counties even fell. In accordance with the classification of natural breaks, urbanization level growth was divided into four classes (negative growth, low growth, medium growth and high growth, with dividing points at $0 \%, 10 \%$ and $20 \%$ ). As can be seen from Figure 4, urbanization in the northern part of the Northwest Border Region and some parts of the Southwest Border Region increased rapidly; however, some counties in the southern part of the Northwest Border Region, the eastern part of the North Border Region

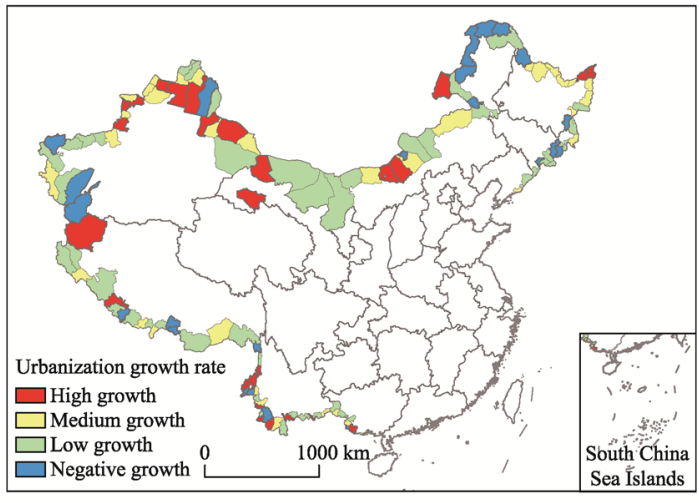

Figure 4 Urbanization growth rate in China's border areas, 2000-2015

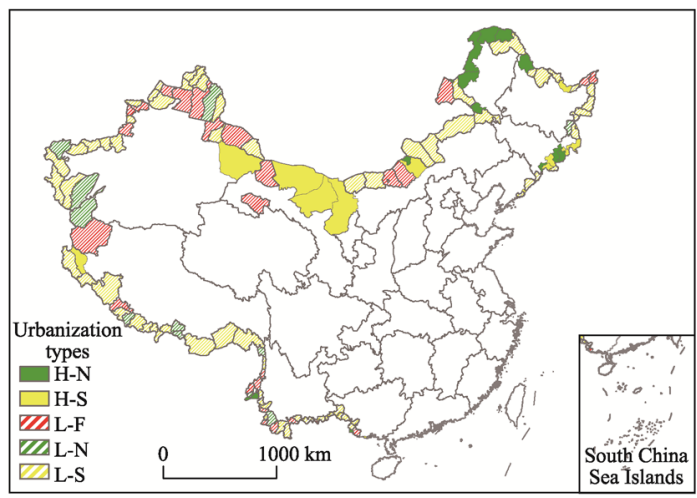

Figure 5 Spatial characteristics of development types for China's border areas' urbanization and the southern part of the Northeast Border Region encountered population loss and, therefore, negative growth.

Based on the level of urbanization in 2000 , border counties can be divided into below-medium level (L) and above-medium level $(\mathrm{H})$, and based on the growth rate of urbanization rate between 2000 and 2015, counties can be divided into negative growth $(\mathrm{N})$, medium-to-low growth $(\mathrm{S})$ and high-speed growth (F). Combining the above two indicators, the urbanization development mode of China's border areas consists of six types. As shown in Figure 5, the $\mathrm{H}-\mathrm{N}$ type is mainly in the Northeast Border Region and the eastern part of the North Border Region; the H-S category is mainly in the southern part of the Northeast Border Region and the western part of the North Border Region; the L-F type is concentrated in the Northwest and Southwest border regions; few counties are in the L-N type, and their distribution is sporadic; the L-S category has the most counties, which are distributed widely. In general, levels of urbanization are low but urbanization is 
increasing at medium and high speeds in the Northwest Border Region and Southwest Border Region; the level of urbanization is the lowest and the growth rate is relatively flat in the Tibet Border Region; the level of urbanization is quite high but urbanization growth is slow or stagnant in the Northeast Border Region and the North Border Region.

\section{Analysis of urbanization drivers in China's border areas}

\subsection{Analysis of overall driving forces}

The factor detector (Table 2) shows that transportation force and industrial force contribute the most to border urbanization, followed by social force, natural force and administrative force, and that market force plays a relatively small role.

Table 2 Factor detection results of urbanization drivers in China's border areas

\begin{tabular}{lcccccc}
\hline & Natural & Admin. & Market & Indust. & Transp. & Social \\
\hline All border areas & $0.103 * * *$ & $0.096^{* * *}$ & $0.058^{* * *}$ & $0.204 * * *$ & $0.224 * * *$ & $0.166^{* * *}$ \\
& $(0.000)$ & $(0.000)$ & $(0.000)$ & $(0.000)$ & $(0.000)$ & $(0.000)$ \\
Northeast & $0.248^{* * *}$ & $0.073 * * *$ & $0.018 *$ & 0.014 & $0.133 * * *$ & $0.069 * * *$ \\
& $(0.000)$ & $(0.000)$ & $(0.068)$ & $(0.135)$ & $(0.000)$ & $(0.000)$ \\
North & $0.092^{* * *}$ & $0.132 * * *$ & $0.199 * * *$ & $0.039 * *$ & $0.190 * * *$ & $0.151 * * *$ \\
& $(0.000)$ & $(0.000)$ & $(0.000)$ & $(0.017)$ & $(0.000)$ & $(0.000)$ \\
Northwest & $0.063 * * *$ & $0.099 * * *$ & $0.048 * * *$ & $0.232 * * *$ & $0.228 * * *$ & $0.016 *$ \\
& $(0.000)$ & $(0.000)$ & $(0.000)$ & $(0.000)$ & $(0.000)$ & $(0.084)$ \\
Tibet & $0.114 * * *$ & $0.036 * *$ & $0.052 * * *$ & 0.017 & 0.040 & $0.072 * * *$ \\
& $(0.000)$ & $(0.042)$ & $(0.007)$ & $(0.324)$ & $(0.256)$ & $(0.000)$ \\
Southwest & $0.037 * * *$ & $0.173 * * *$ & $0.198 * * *$ & $0.064 * * *$ & $0.138 * * *$ & $0.108 * * *$
\end{tabular}

Note: The $p$ value corresponding to each $q$ statistic above is in parentheses. $* * *, * *, *$ indicate significance at $1 \%, 5 \%$ and $10 \%$, respectively.

Transportation is the main driver of urbanization in border areas. Due to the remote location and underdeveloped transport infrastructure of border areas, small improvements in transportation can lead to relatively significant economic and social benefits. For example, by improving their transportation infrastructure, border counties such as Bole and Pingxiang have attracted people and logistics and become business and trade hubs, thereby greatly promoting urban development.

Similar to urbanization in other regions, industrial force is one of the major factors in the development of urbanization in border areas (Liu and Yang, 2012; Gao et al., 2018). Specifically, Dandong, Donggang, Jidong, Mishan and other counties in the Northeast Border Region have higher levels of industrial development, which has led to higher levels of urbanization; whereas, Lhozhag, Cona and Kangmar counties in the Tibet Border Region have small-scale industry and severely lagging development, which has restricted urbanization.

Social and natural forces shape the livable environment through social services and the natural environment, which attract populations to cities, but they have a relatively small effect on urbanization in border areas. Local and national policy support can provide certain 
development advantages to border areas, but due to a lack of preferential policies for border areas in China in recent years, administrative force has had a limited effect on urbanization in border areas across a relatively large area.

Market force also has a limited effect on urbanization in border areas, which is related to the limited size of industries in those areas, backward transportation infrastructure, insufficient supplies of tradable goods and insufficient hinterland support. These result in the market potential of border areas not being realized.

The interaction detection results (Figure 6) show the interactions between the six types of driving forces in the process of promoting urbanization in border areas, mainly nonlinear enhancement with some bilinear enhancement. The development of urbanization in border areas is the result of coordinated and overlapping influences of various factors, such as the environment, economics, government policy, industry, transportation and society. Of these, interactions between natural and other forces are the strongest, indicating that natural environment and resources are still fundamental for urban development and affect the determinant levels of other drivers. The enhancement effect of interactions between market and transportation force as well as between administrative and market force is significant, mainly because border trade activities require connected supply and sales markets via transportation routes, and large markets and convenient transportation infrastructure are mutually promoting and thus jointly increase the urbanization levels of border areas. In addition, administrative factors, such as cross-border economic cooperation zones, free-trade areas and border economic cooperation zones in border areas are conducive to expanding the size of markets and increasing regional market drivers, thereby promoting urbanization.

\begin{tabular}{|c|c|c|c|c|c|c|}
\hline & Natural & Admin. & Market & Indust. & Transp. & Social \\
\hline Natural & 0.119 & 0.224 & 0.201 & 0.348 & 0.399 & 0.346 \\
\hline Admin. & 0.224 & 0.096 & 0.183 & 0.275 & 0.341 & 0.249 \\
\hline Market & 0.201 & 0.183 & 0.058 & 0.256 & 0.320 & 0.239 \\
\hline Indust. & 0.348 & 0.275 & 0.256 & 0.204 & 0.339 & 0.296 \\
\hline Transp. & 0.399 & 0.341 & 0.320 & 0.339 & 0.224 & 0.330 \\
\hline Social & 0.346 & 0.249 & 0.239 & 0.296 & 0.330 & 0.166 \\
\hline
\end{tabular}

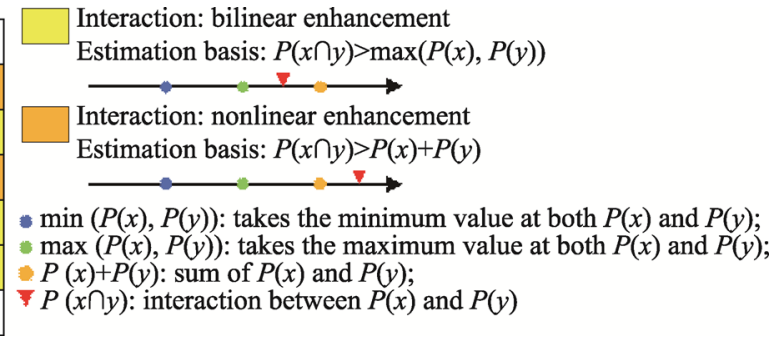

Figure 6 Interaction detection results of urbanization drivers in China's border areas

Note: The diagonal values in the table (in white boxes) are the individual explanatory powers ( $q$ statistics) of each driver, and the non-diagonal values are the explanatory power ( $q$ statistics) of interactions between two driving forces.

\subsection{Analysis of driving forces by region}

In the urbanization of counties in the Northeast Border Region, transportation, administrative, social and natural forces all play significant roles, market force plays a lesser significant role, and industrial force has the least significant influence. The largest contribution is from natural force, due to relatively abundant precipitation, vast plains and abundant arable land, which provide favorable conditions for the development of towns along the northeast border. The second largest contribution is from transportation force, mainly because the ports of Suifenhe, Heihe, Hunchun, Helong and Dandong in China's northeast provide international connections, facilitating domestic and foreign commodity trade and stimulating urban development through spillover effects. Market force, meanwhile, play less of a role in urbanization in the northeast because neighboring North Korea is largely closed off, Russia 
has a sparse population and border markets in neighboring countries offer limited trade. In addition, with the gradual weakening of traditional machinery and equipment manufacturing industries in the northeast and lack of competitiveness of emerging industries, industrial force has not provided effective impetus to urbanization.

In the urbanization of the North Border Region, transportation, market, administrative, social and natural force have played significant roles; whereas, industrial force has played a less significant role. Market and transportation drivers are the largest contributors because border economic cooperation zones and border ports, such as Erlianhot and Manzhouli, are important in connecting China with the rest of Eurasia (such as via the China-MongoliaRussia Economic Corridor). Both these drivers have been effective in promoting the development of local urban areas.

In the urbanization of the Northwest Border Region, industrial, transportation, natural, administrative and market forces have played significant roles; whereas, social force has played a less significant role. Industrial and transportation forces are the largest contributors, mainly due to the Northwest Border Region being a transportation hub for many international economic corridors along the Silk Road Economic Belt. For example, important ports for overseas trade such as Khorgas, Bole (Alashankou) and Tacheng have upgraded the transportation status of their host counties, and strengthened their connectivity to domestic and international transportation networks, which have effectively promoted urbanization. In addition, the Northwest Border Region is home to several 5A-certified scenic spots, such as Koktokay (Fuyun) and Kanas (Habahe), the customs and culture of ethnic minorities in the region have proved popular with tourists, providing opportunities for cross-border tourism, which have greatly promoted urbanization.

In the urbanization of the Tibet Border Region, natural, social and market forces have played significant roles, while transportation and administrative forces have played a relatively significant role, but the influence of industrial and natural forces have not been significant. Compared to other border regions, however, with the exception of natural force, the effect of these driving forces has been relatively small. Counties in the Tibet Border Region are separated from neighboring countries by the Himalayas. They have poor natural conditions, small populations, inadequate transportation, and lagging socio-economic development. Generally, the various driving forces are weak. Most border counties in Tibet have been unable to cultivate drivers that can effectively promote urbanization, which is why both the level and speed of urbanization in the region remain low.

In the Southwest Border Region, the six major driving forces of urbanization have all played significant roles. Market and administrative forces contribute the most, followed by social and transportation forces, but industrial and natural forces contribute relatively little. Because the region includes Ruili, Mengla, Dongxing, Pingxiang and other border economic cooperation zones, as well as key development and opening-up experimental zones, cross-border economic cooperation zones and free-trade areas, national policies and local financial investment have supported urban development in the region. The Southwest Border Region is close to Southeast Asia's vast international market and has opened up well, and development of the China-Indochina Peninsula Economic Corridor has improved domestic and international transportation connectivity at the southwest border, promoted the flow of goods and funds, and expanded port cities and their areas of influence in the hinterland. In 
addition, cross-border cultural, economic and trade exchanges are facilitated by the relatively flat topography of the Southwest Border Region, connections with neighboring counties via rivers such as the Nujiang River and Lancang River, the high population density of Southeast Asian countries and concentrations of ethnic groups that span borders. These market, administrative, social and economic factors have played an important role in promoting urbanization in the Southwest Border Region and in making it the fastest urbanizing region.

Taken together, transportation force plays an important role in the urbanization process, except in the Tibet Border Region; administrative, social and market forces play a relatively important role in urbanization in the North and Southwest Border Regions; natural force plays an important role in the urbanization of the Northeast and Tibet Border Regions; and industrial force plays a relatively important role in the urbanization of the Northwest Border Region only.

It can be seen, then, that transportation force is an important driver of urbanization in border areas generally, as border counties can achieve domestic and international connectivity to transport networks by opening ports and constructing important hubs along land routes, which can produce spillover effects, such as circulating and clustering factors of production, thereby promoting urban development. Administrative force plays a limited role in promoting urbanization in border areas, but that role is more notable in border areas with higher local fiscal expenditure. The role of social and market forces in the urbanization of border areas depends on the socio-economic conditions of neighboring countries. Border areas with close social, cultural and economic connections with neighboring countries have stronger social and market forces. As the foundation of urban development, different natural conditions have different effects on urbanization, such as in the most urbanized Northeast Border Region and the least urbanized Tibet Border Region. Due to the relatively backward industrial development of most border areas, however, natural and industrial forces have small impetus on urbanization.

The results of the interaction detection analysis (Figure 7) show the following:

First, the explanatory power of interactions between driving forces on the level of urbanization in the Northeast Border Region is non-linear enhanced. Explanatory power was enhanced significantly after interactions between natural and market forces, between natural and administrative forces, between industrial and transportation forces, between administrative and market forces and between administrative and industrial forces. Good natural conditions are conducive to exploiting market and administrative drivers. As the Northeast Border Region has a good foundation of industrial development, transportation construction and industrial development are compatible, which can effectively promote urban development. In addition, the policies and fiscal expenditure of the Northeast Border Region are conducive to market expansion and industrial development, which can effectively promote the process of urbanization.

Second, the explanatory power of interactions between driving forces on the urbanization level in the North Border Region largely has a non-linear enhancement effect. Explanatory power is enhanced significantly after interactions between industrial force and transportation force, because the North Border Region has an established foundation of industry, and local raw material processing and corresponding products can circulate with the support of transportation, thereby promoting urban development together. 


\begin{tabular}{|c|c|c|c|c|c|c|}
\hline & Natural & Admin. & Market & Indust. & Transp. & Social \\
\hline Natural & 0.248 & 0.433 & 0.397 & 0.384 & 0.426 & 0.329 \\
\hline Admin. & 0.433 & 0.073 & 0.191 & 0.188 & 0.216 & 0.196 \\
\hline Market & 0.397 & 0.191 & 0.018 & 0.077 & 0.197 & 0.159 \\
\hline Indust. & 0.384 & 0.188 & 0.077 & 0.014 & 0.250 & 0.153 \\
\hline Transp. & 0.426 & 0.216 & 0.197 & 0.250 & 0.133 & 0.222 \\
\hline Social & 0.329 & 0.196 & 0.159 & 0.153 & 0.222 & 0.069 \\
\hline
\end{tabular}

(a) Northeast Border Region

\begin{tabular}{|c|c|c|c|c|c|l|}
\hline & Natural & Admin. & Market & Indust. & Transp. & Social \\
\hline Natural & 0.063 & 0.216 & 0.195 & 0.360 & 0.336 & 0.131 \\
\hline Admin. & 0.216 & 0.099 & 0.270 & 0.350 & 0.338 & 0.171 \\
\hline Market & 0.195 & 0.270 & 0.048 & 0.332 & 0.472 & 0.080 \\
\hline Indust. & 0.360 & 0.350 & 0.332 & 0.232 & 0.400 & 0.259 \\
\hline Transp. & 0.336 & 0.338 & 0.472 & 0.400 & 0.228 & 0.316 \\
\hline Social & 0.131 & 0.171 & 0.080 & 0.259 & 0.316 & 0.016 \\
\hline
\end{tabular}

(c) Northwest Border Region

\begin{tabular}{|c|c|c|c|c|c|c|}
\hline & Natural & Admin. & Market & Indust. & Transp. & Social \\
\hline Natural & 0.037 & 0.281 & 0.280 & 0.183 & 0.228 & 0.229 \\
\hline Admin. & 0.281 & 0.173 & 0.306 & 0.252 & 0.304 & 0.274 \\
\hline Market & 0.280 & 0.306 & 0.198 & 0.292 & 0.350 & 0.317 \\
\hline Indust. & 0.183 & 0.252 & 0.292 & 0.064 & 0.229 & 0.164 \\
\hline Transp. & 0.228 & 0.304 & 0.350 & 0.229 & 0.138 & 0.279 \\
\hline Social & 0.229 & 0.274 & 0.317 & 0.164 & 0.279 & 0.108 \\
\hline
\end{tabular}

(e) Southwest Border Region

\begin{tabular}{|l|c|c|c|c|c|c|}
\hline & Natural & Admin. & Market & Indust. & Transp. & Social \\
\hline Natural & 0.092 & 0.285 & 0.390 & 0.227 & 0.398 & 0.275 \\
\hline Admin. & 0.285 & 0.132 & 0.359 & 0.264 & 0.372 & 0.284 \\
\hline Market & 0.390 & 0.359 & 0.199 & 0.278 & 0.351 & 0.323 \\
\hline Indust. & 0.227 & 0.264 & 0.278 & 0.039 & 0.377 & 0.254 \\
\hline Transp. & 0.398 & 0.372 & 0.351 & 0.377 & 0.190 & 0.382 \\
\hline Social & 0.275 & 0.284 & 0.323 & 0.254 & 0.382 & 0.151 \\
\hline
\end{tabular}

(b) North Border Region

\begin{tabular}{|l|r|r|r|r|r|r|}
\hline & Natural & Admin. & Market & Indust. & Transp. & Social \\
\hline Natural & 0.114 & 0.276 & 0.378 & 0.205 & 0.229 & 0.261 \\
\hline Admin. & 0.276 & 0.036 & 0.242 & 0.112 & 0.140 & 0.158 \\
\hline Market & 0.378 & 0.242 & 0.052 & 0.137 & 0.154 & 0.203 \\
\hline Indust. & 0.205 & 0.112 & 0.137 & 0.017 & 0.157 & 0.148 \\
\hline Transp. & 0.229 & 0.140 & 0.154 & 0.157 & 0.040 & 0.200 \\
\hline Social & 0.261 & 0.158 & 0.203 & 0.148 & 0.200 & 0.072 \\
\hline
\end{tabular}

(d) Tibet Border Region

Interaction: bilinear enhancement

Estimation basis: $P(x \cap y)>\max (P(x), P(y))$

Interaction: nonlinear enhancement

Estimation basis: $P(x \cap y)>P(x)+P(y)$

$$
\longrightarrow
$$

- $\min (P(x), P(y))$ : takes the minimum

value at both $P(x)$ and $P(y)$;

max $(P(x), P(y))$ : takes the maximum

value at both $P(x)$ and $P(y)$;

$P(x)+P(y)$ : sum of $P(x)$ and $P(y)$;

$\checkmark P(x \cap y)$ : interaction between $P(x)$ and $P(y)$

Figure 7 Interaction detection results of urbanization drivers in China's border areas

Note: The diagonal values in the table (in white boxes) are the individual explanatory powers ( $q$ statistics) of each driver, and the non-diagonal values are the explanatory power ( $q$ statistics) of interactions between two driving forces.

Third, explanatory power is enhanced significantly after interactions between market and transportation forces in the Northwest Border Region, followed by interactions between administrative and market forces. Because Khorgas and Alashankou on China's northwest border are important nodes in the New Eurasian Land Bridge and China-Central Asia-West Asia International Economic Corridor, they have direct connections to Central Asian and European markets. Large markets and convenient transportation conditions are mutually reinforcing, so they jointly increase local urbanization levels. In addition, policies on border economic cooperation zones, free-trade areas and cross-border economic cooperation zones are conducive to expanding markets, increasing regional market drivers and promoting urbanization.

Fourth, explanatory power is enhanced markedly after interactions between driving factors in the Tibet Border Region. Specifically, explanatory power increases greatly after interactions between natural and market forces and to a slightly lesser extent after interactions between administrative and market forces, indicating that the harsh natural environment and 
resource conditions of the Tibet Border Region have a strong negative impact on market expansion. Although the direct driving effect of administrative force on urbanization is low, it indirectly promotes urbanization by expanding market potential.

Fifth, the enhancement effect of interactions between driving forces is lower in the Southwest Border Region than in other regions, but explanatory power is enhanced significantly by interactions between natural and social forces, between natural and industrial forces, and between natural and administrative forces. Although natural force has weak explanatory power on the urbanization of the Southwest Border Region, it is the basic influencing factor on the distribution and flow of the border population and the effect of policy implementation. Its explanatory power gets stronger when interacting with social and administrative forces.

There is an evident mutually reinforcing effect between urbanization drivers in border areas, mainly non-linear in character but bilinear in some cases. The interactions of natural force are the strongest. With the exception of the Northwest Border Region, interactions between natural force and other driving forces have a nonlinear enhancement effect with stronger interactions. This indicates that the natural environment is still a basic factor in urbanization.

\section{Conclusions and discussion}

\subsection{Conclusions}

China's border areas are important gateways between the hinterland and the outside world. They are key areas for building a moderately prosperous society in all respects in China and an important part of optimizing the urban spatial pattern. The unique locations of border areas make the process and driving forces of urbanization quite different from other parts of the country. Further research is urgently needed in this area. Based on an analysis of a large volume of data, this study conducted an in-depth analysis of the pattern and driving mechanisms of urbanization in China's border areas between 2000 and 2015. The study found the following:

First, in the study period, the level of urbanization in border areas was lower than the national average, and there was a widening gap. Border areas are suffering from lagging urban development and insufficient dynamism, and some areas are even experiencing population loss.

Second, during the same period, spatial differences in the urbanization of border areas narrowed significantly, with the coefficient of variation $(\mathrm{CV})$ value falling from 0.713 to 0.520. Looking at specific regions, the level of urbanization is low in the Northwest Border Region and Southwest Border Region, but urbanization is occurring relatively quickly; the urbanization level in the Tibet Border Region is the lowest, and its urbanization growth is flat; the levels of urbanization in the Northeast Border Region and North Border Region are slightly higher, but the rate of urbanization is slow or even stagnant.

Third, transportation force and industrial force are the largest contributors to urbanization in border areas, and market force has the smallest effect. There is clear mutual reinforcement between the various driving forces.

Fourth, the main drivers of urbanization in the Northwest Border Region and the South- 
west Border Region are industrial and transportation forces, market and administrative forces respectively. They have formed the driving mechanisms which can effectively boost the stage of urbanization in these areas. Natural, social and economic conditions in the Tibet Border Region are weak, so they have not become drivers that contribute strongly to urbanization. Transportation force in the Northeast Border Region and North Border Region has made a significant contribution to urbanization, and its interactions with market and industrial forces have a clear enhancement effect.

\subsection{Discussion}

Studies have found that China's eastern region has successfully seized the opportunities presented by globalization to achieve rapid industrialization and urbanization. The main drivers of urbanization in the region are its economic level, industrial structure, foreign investment, fixed-asset investment, population size, policy orientation, locational advantages and technological innovation (Xue and Yang, 1997; Zhou et al., 2019). Unlike the eastern region, China's border areas are restricted by the natural environment, transport infrastructure and the geo-economic environment, putting them on the periphery of China's opening-up drive. As a result, the main driving force of urbanization in border areas is transportation force, especially in the Northwest Border Region and North Border Region, which have a solid foundation of urbanization. This is because construction of transport infrastructure can improve the accessibility of otherwise remote border areas, which facilitates urbanization, increases flows of factors of production and promotes concentrations of factors of production and people. The role of market force in promoting urbanization in border areas is relatively small, with a notable effect only in the North Border Region and Southwest Border Region, both of which have reasonably good market conditions. There are positive interactions between driving forces of urbanization in border areas, indicating that there is a typical "bucket effect" among drivers, which means that a change in any one factor can influence the speed of urbanization. As such, multiple driving mechanisms need to be considered in the urbanization process in border areas in future so that an appropriate development model can be selected based on local industry and the local geological and ecological environment.

For regions with relatively high levels of urbanization, such as the Northeast Border Region and the North Border Region, it is recommended that governments formulate more preferential tax and fee policies for local border trade; create more special function platforms, such as border town trade areas, border economic cooperation zones and key experimental zones for development and opening-up; actively cultivate a market environment in border areas; promote the interaction of multiple driving forces, such as transportation, market and administrative forces; and jointly promote the development of urbanization in these border areas. For areas with lower levels of urbanization but with better development, such as the Northwest Border Region and the Southwest Border Region, due to their better policy and market conditions, it is recommended that governments urge the construction of more cross-border transport corridors under the Belt and Road Initiative, strengthen links between border areas and domestic and international markets, and enhance interactions between transportation and existing industrial and market forces, so as to promote urbanization. Due to the Tibet Border Region's lack of resources, poor natural environment and poor ac- 
cessibility, it is recommended that governments further increase subsidies for border residents, strengthen construction of local transport infrastructure, increase social security, such as education and medical care, stem population loss in border areas, and use administrative force in combination with industrial and social forces - primarily tourism - to promote urbanization.

\section{References}

Brunet-Jailly E, 2005. Theorizing borders: An interdisciplinary perspective. Geopolitics, 10(4): 633-649.

Cao Guangzhong, Liu Tao, 2011. Rising role of inland regions in China's urbanization in the 21st century: The new trend and its explanation. Acta Geographica Sinica, 66(12): 1631-1643. (in Chinese)

Chen Aimin, 2016. Urbanization in China and the case of Fujian Province. Modern China, 32(1): 99-130.

Chen Mingxing, Lu Dadao, Zhang Hua, 2009. Comprehensive evaluation and the driving factors of China's urbanization. Acta Geographica Sinica, 64(4): 387-398. (in Chinese)

Chen Zhongnuan, Gao Quan, Wang Shuai, 2014. The comprehensive evaluation of China's urbanization and spatial difference in provincial level. Economic Geography, 34(6): 54-59. (in Chinese)

Fang Yiping, Fan Jie, Shen Maoying et al., 2012. Gradient effect on farmers' income in the mountain areas and its implication for poverty alleviation strategies: Empirical analysis from the upper reach of Minjiang River, China. Journal of Mountain Science, 9(6): 869-878.

Gao Jinlong, Bao Jingwei, Liu Yansui et al., 2018. Regional disparity and the influencing factors of land urbanization in China at the county level, 2000-2015. Acta Geographica Sinica, 73(12): 2329-2344. (in Chinese)

$\mathrm{Hu}$ Zhiding, Luo Huasong, Li Cansong et al., 2012. Triple functions of country border and its concerning optimized combination under the perspective of geopolitical security. Human Geography, 27(3): 73-77. (in Chinese)

Huang Jianying, 2010. Study on the development pattern of border minority county economy. Heilongjiang National Series, (4): 42-47. (in Chinese)

Ji Xiaofeng, Jiang Li, Chen Fang, 2017. Spatio-temporal cooperative evolution analysis of transportation superiority and county urbanization in Yunnan Province. Scientia Geographica Sinica, 37(12): 1875-1884. (in Chinese)

Kelejian H, Tavlas G S, Petroulas P, 2012. In the neighborhood: The trade effects of the Euro in a spatial framework. Regional Science and Urban Economics, 42(1/2): 314-322.

Li Cansong, Hu Zhiding, Ge Yuejing et al., 2014. Progress of foreign political geography in border security studies. Tropical Geography, 34(4): 454-462. (in Chinese)

Li Hong, Zhang Jun, Ou Xiaojing, 2017. Spatiotemporal evolution of county urbanization and migration of population in border province: A case study of Guangxi. Tropical Geography, 37(2): 163-173. (in Chinese)

Li Yanqin, Shu Sheng, 2015. Focus on frontier research in China under the perspective of tourism. Geographical Research, 34(3): 407-421. (in Chinese)

Lin G C, 2002. The growth and structural change of Chinese cities: A contextual and geographic analysis. Cities, 19(5): 299-316.

Liu Yansui, Yang Ren, 2012. The spatial characteristics and formation mechanism of the county urbanization in China. Acta Geographica Sinica, 67(8): 1011-1020. (in Chinese)

Ma Yong, 2003. Elementary introduction to the selection of the economic developmental patterns in the border areas. N.W. Ethno-National Studies, 37(2): 98-106. (in Chinese)

Mao Hanying, 2013. Geopolitical and geo-economic situation around and China's strategies. Progress in Geography, 33(3): 289-302. (in Chinese)

Qiu Yunzhi, 2005. Study on tourism urbanization in minority areas. Journal of Southwest University for Nationalities (Humanities and Social Science), (10): 32-34. (in Chinese)

Rumley D, Minghi J, 1991. The Geography of Border Landscapes. London: Routledge. 
Shen L, Cheng S K, Gunson A J et al., 2005. Urbanization, sustainability and the utilization of energy and mineral resources in China. Cities, 22(4): 287-302.

Song Tao, Cheng Yi, Liu Weidong et al., 2017. Spatial difference and mechanisms of influence of geo-economy in the border areas of China. Journal of Geographical Sciences, 27(12): 1463-1480.

Song Zhouying, Che Shuyun, Wang Jiaoe et al., 2015. Spatiotemporal distribution and functions of border ports in China. Progress in Geography, 34(5): 589-597. (in Chinese)

$\mathrm{Su}$ Xiaobo, 2013. From frontier to bridgehead: Cross-border regions and the experience of Yunnan, China. International Journal of Urban and Regional Research, 37(4): 1213-1232.

Sun Dongqi, Chen Mingxing, Chen Yufu, 2016. China's new-type urbanization and investment demand prediction analysis, 2015-2030. Acta Geographica Sinica, 71(6): 1025-1044. (in Chinese)

Tang Jianzhong, Zhang Bing, Chen Ying, 2002. The boundary effect and cross-border subregional economic cooperation: A case study of East Asia. Human Geography, 17(1): 8-12. (in Chinese)

Wang Fahui, Jin Fengjun, Zeng Guang, 2003. Geographic patterns of air passenger transport in China. Scientia Geographica Sinica, 23(5): 519-525. (in Chinese)

Wang Jiankang, Gu Guofeng, Yao Li et al., 2016. Analysis of new urbanization's spatial pattern evolution and influence factors in China. Scientia Geographica Sinica, 36(1): 63-71. (in Chinese)

Wang Jiaoe, Jiao Jingjuan, Ma Li, 2018. An organizational model and border port hinterlands for the China-Europe Railway Express. Journal of Geographical Sciences, 28(9): 1275-1287.

Wang Jinfeng, Li Huxin, George Christakos et al., 2010. Geographical detectors based health risk assessment and its application in the neural tube defects study of the Heshun region, China. International Journal of Geographical Information Science, 24(1): 107-127.

Wang Yang, Fang Chuanglin, Wang Zhenbo, 2012. The study on comprehensive evaluation and urbanization division at county level in China. Geographical Research, 31(7): 1305-1316. (in Chinese)

Wu Yifan, Liu Yansui, Li Yurui, 2018. Spatio-temporal coupling of demographic-landscape urbanization and its driving forces in China. Acta Geographica Sinica, 73(10): 1865-1879. (in Chinese)

Xue Desheng, Zeng Xuanjun, 2016. Evaluation of China's urbanization quality and analysis of its spatial pattern transformation based on the modern life index. Acta Geographica Sinica, 71(2): 194-204. (in Chinese)

Xue Fengxuan, Yang Chun, 1997. Exo-urbanization: The case of the Zhujiang River Delta. Acta Geographica Sinica, 52(3): 193-206. (in Chinese)

Yao Shimou, Wang Chen, Zhang Luocheng et al., 2008. The influencing factors of resources and environments in the process of urbanization of China. Progress in Geography, 27(3): 94-100. (in Chinese)

Zhai Shunhe, Guo Wenjiong, Jing Puqiu, 2010. Driving force, characteristics and strategic orientation of urbanization in resource-based areas: A case of study of Shanxi Province. City Planning Review, 34(9): 67-72. (in Chinese)

Zhong Linsheng, Zhang Shengrui, Shi Yuqin et al., 2014. Evaluation and utilization strategies of land border tourism resources in China. Resources Science, 36(6): 1117-1124. (in Chinese)

Zhou Chunshan, Wang Yuqu, Xu Qiying et al., 2019. The new process of urbanization in the Pearl River Delta. Geographical Research, 38(1): 45-63. (in Chinese)

Zhou Wenting, Liu Yungang, Wu Yinshan, 2018. Border space construction between Shenzhen and Hong Kong based on the "one country, two systems" policy: A case study of Chung Ying Street area. Geographical Research, 37(11): 2288-2304. (in Chinese) 